\title{
Inclusão e Exclusão no Contexto da Educação Física Escolar ${ }^{1}$
}

\author{
José Francisco Chicon*
}

\begin{abstract}
Resumo: $O$ artigo elenca os principais acontecimentos históricos quanto ao caminho percorrido pela Educação Física no âmbito escolar analisando aspectos relacionados com o eixo inclusão/exclusão que permeou a Educação Física na trajetória sócio-histórica. Esse diálogo com o passado não implica esclarecer o presente, não supõe ensinar como deveria ter sido, apenas relata o que foi $e$ mostra que os acontecimentos não se dão de forma arbitrária, mas existe relacionamento entre eles. $O$ estudo revela o quanto na história da Educação Física os alunos com deficiência foram excluídos do processo ensinoaprendizagem e deixa pistas para a superação dessa exclusão.
\end{abstract}

Palavras-chave: Educação Física. História. Pessoas portadoras de deficiência.

\section{INTRODUÇÃo}

$\mathrm{Na}$ construção deste artigo citamos os principais acontecimentos históricos que situam o caminho percorrido pela Educação Física no âmbito escolar, analisando aspectos relacionados com o eixo inclusão/exclusão que a permeou na trajetória sócio-histórica.

Este breve diálogo com o passado não implica que se esclareça o presente, não supõe que se ensine como deveria ter sido. Ele nos relata o que foi e mostra que os acontecimentos não se dão de forma arbitrária, mas existe relacionamento entre eles. Também, ao retomar o passado se poderá, talvez, clarificar o presente quanto

${ }^{1} \mathrm{O}$ artigo é resultante da construção da matriz teórica que subsidiou as análises e discussões desenvolvidas na tese de doutorado do autor: Inclusão na Educação Física escolar: construindo caminhos. 2005. 420 f. Tese (Doutorado em Educação) - Programa de PósGraduação em Educação/Faculdade de Educação da USP, São Paulo, 2005.

"Professor Adjunto do Departamento de Ginástica. Integrante do Laboratório de Estudos em Educação Física da Universidade Federal do Espírito Santo, Vitória, ES, Brasil. E-mail: chiconjf@yahoo.com.br 
ao velho que nele persiste. Porém, é preciso ter claro que as fases e os períodos em que ocorreram os fatos históricos não podem ser demarcados de modo estanque.

Ao longo da história do homem, a atividade física, considerada de forma ampla, e mesmo de Educação Física, surgem em todos os momentos, em maior ou menor grau, com maior ou menor institucionalização. Entretanto, desconsiderando-se a Antiguidade Grega, foi nas últimas décadas do século XVIII, e em especial durante o século XIX, que a Educação Física experimentou um decisivo impulso no sentido de sua sistematização e institucionalização como uma forma de educação no mundo ocidental. O epicentro desse crescimento é a Europa, onde são desenvolvidos, no continente, os sistemas ginásticos (ginástica alemã, sueca e francesa), e na Inglaterra com o movimento esportivo, e daí espalhou-se por todo o mundo. Esse processo deu-se num momento histórico de grandes mudanças políticas, econômicas e sociais, e com elas relaciona-se, sofrendo também a influência do novo pensamento pedagógico do século XVIII, com o advento dos chamados educadores naturalistas e filantrópicos.

Em Soares et al. (1992), encontramos que, ao longo do século XVIII, já havia a preocupação de incluir as atividades corporais na escola. No entanto, só no século XIX tal preocupação se materializou, concorrendo como fator decisivo para isso a criação de Escolas de Ginástica na forma de associações livres. Com a implementação dessas escolas e sua difusão em nível mundial, os exercícios físicos passam a sofrer um grande desenvolvimento, que faz com que a importância das práticas corporais seja cada vez mais reconhecida. Entretanto, essa prática não havia adentrado os limites do âmbito escolar. A pressão para que isso ocorresse, dá-se pelo desenvolvimento das Escolas de Ginástica, que passam a exigir a ginástica no ensino formal.

Assim, existe a necessidade de sistematizar esse conhecimento, as práticas corporais, as atividades físicas, de acordo com as características peculiares da instituição escolar, uma vez que as propostas até então elaboradas referiam-se a outros âmbitos que não a escola.

Movimento, Porto Alegre, v. 14, n. 01, p. 13-38, janeiro/abril de 2008. 
Surgem, desse modo, segundo Soares et al. (1992), as primeiras sistematizações sobre os exercícios físicos denominados de métodos ginásticos, tendo como autores mais conhecidos o sueco Ling, o francês Amoros e o alemão Spiess, com contribuições advindas de fisiologistas, como Demeny e Marey, e também de médicos, como Tissié, e ainda de professores de música, como Dalcroze.

Esses autores citados tiveram o mérito de aliar o desenvolvimento da ginástica ou Educação Física na escola à garantia de um espaço de respeito e consideração da área perante os demais componentes curriculares. Dessa maneira, a Educação Física ministrada na escola começou a ser vista como importante instrumento de aprimoramento físico dos indivíduos que, "fortalecidos" pelo exercício corporal, que em si gera saúde, estariam mais aptos para contribuir com a grandeza da indústria nascente, dos exércitos, assim como com a prosperidade da Pátria.

Desenvolver e fortalecer física e moralmente os indivíduos era, portanto, uma das funções a serem desempenhadas pela Educação Física no sistema educacional e um dos aspectos que a identificava. Outro aspecto que a caracterizava era o seu caráter científico conferido a partir do referencial oriundo das ciências biológicas, referencial este que sustentava seu conteúdo de ensino, os métodos ginásticos, compostos de séries de exercícios elaborados a partir dos critérios rígidos próprios daquelas ciências.

Esses métodos ginásticos, quando colocados em prática pelo instrutor (professor), tratavam todos os participantes das sessões de forma igual (homogênea), estereotipada, com a mesma intensidade, tendo os alunos que repetir os gestos mecânicos dele, desconsiderando as diferenças e necessidades de cada um. "O processo de ensino das lições de Educação Física exigia do instrutor a exposição oral e demonstração minuciosa e da classe, imitação precisa” (FERREIRA NETO, 1999, p. 63-64). Portanto, não havia espaço-tempo para acolher as diferenças.

Nogueira (1990, p. 170) ressalta que, na Europa, foi decisiva a influência das instituições militares nas origens escolares da Educação

Movimento, Porto Alegre, v. 14, n. 01, p. 13-38, janeiro/abril de 2008. 
Física, pois nelas os exercícios eram já bastante sistematizados. Assim,

[...] assistiu-se, no século XIX, a uma quase que superposição $[. .$.$] da ginástica escolar às práticas$ militares; fenômeno ao qual provavelmente não estiveram indiferentes as preocupações com a instalação de uma ordem escolar [...].

Ferreira Neto (1999) também segue nessa direção. Para ele, o Brasil, no período compreendido entre 1850-1930, se esforçava para fazer chegar às camadas mais ampliadas da população as conquistas européias no campo da economia, da indústria, do saneamento básico, da saúde, da educação, enfim, das liberdades individuais e coletivas. A apropriação dessas conquistas permitiria ao País superar o modelo agro exportador e inserir-se no modelo urbano-industrial, para o qual se exigia um projeto nacional do qual fazia parte a constituição de um "novo homem brasileiro", no que a Educação Física foi coadjuvante, por meio dos médicos/higienistas e, de modo sistemático, dos militares.

Castellani Filho (1988, p. 38-39) corrobora essa afirmação ao explicitar em seu entendimento, o seguinte:

[...] o que levou por associar a Educação Física à Educação do Físico, à Saúde Corporal, não se deve exclusivamente e nem tampouco prioritariamente, aos militares. A eles, nessa compreensão, juntavamse os médicos que, mediante uma ação calcada nos princípios da medicina social de índole higiênica, imbuíram-se da tarefa de ditar à sociedade, através da instituição familiar, os fundamentos próprios ao processo de reorganização daquela célula social. Ao assim procederem, ao tempo em que denunciavam os malefícios da estrutura familiar do período colonial, auto proclamavam-se a mais competente das categorias profissionais para redefinir os padrões de conduta física, moral e intelectual da 'nova' família brasileira

Higiene, raça e moral pontuavam as propostas pedagógicas e legais que contemplavam a Educação Física escolar em suas primeiras iniciativas.

Movimento, Porto Alegre, v. 14, n. 01, p. 13-38, janeiro/abril de 2008. 
Em 1882, o Projeto $n^{\circ} 224$, "Reforma do Ensino Primário e Várias Instituições Complementares da Instrução Pública", recebeu um Parecer de Rui Barbosa, que evidencia o seu caráter obrigatório e recomenda a instituição de uma seção especial de ginástica na escola normal, a extensão obrigatória da ginástica a ambos os sexos, na formação do professorado e nas escolas primárias de todos os graus - preservando, porém, para a mulher, as "funções" a serem por ela desempenhadas na sociedade, quais sejam, as de "mulher/mãe", de reprodutora dos filhos da Pátria. A ginástica destinada à mulher deveria, então, acentuar a sua forma feminina e, desse modo, co mpor o ideário burguês sobre as diferenças da mulher em relação ao homem: inserção da ginástica nos programas escolares como matéria de estudo e equiparação, em categoria e autoridade, dos professores de ginástica, com os de todas as outras disciplinas (BARBOSA, 1952, apud BETTI, 1991).

Os elementos apontados por Rui Barbosa expressam as preocupações da elite brasileira com a regeneração da raça, com a procriação, com a saúde física de homens e mulheres, entendidos como soldados da Pátria. A Educação Física, no âmbito dessas preocupações, surge como instrumento ideal para forjar indivíduos saudáveis e úteis para ocupar funções específicas na produção.

\section{DISCUTINDO O PROCESSO DE INCLUSÃO/EXCLUSÃO NA EDUCAÇÃO FÍSICA}

Profundamente moralistas, as idéias sobre os "benefícios" da ginástica são oriundas do pensamento médico-higienista e de uma visão "medicalizada" do ser humano. Esse pensamento normativo, disciplinador e moral teve papel determinante nas primeiras sistematizações sobre a ginástica, sobre a "educação física" dos indivíduos. $\mathrm{E}$, também, influenciou de forma decisiva, para que as pessoas com necessidades educacionais especiais (NEEs) fossem concebidas como doentes, que precisam ser curadas, habilitadas e preparadas, para só então participar da vida em sociedade, devendo, nesse meio tempo, receber atendimento em instituições segregadoras, como as Associações de Pais e Amigos dos Excepcionais (APAEs), instituições educacionais para surdos-mudos e cegos, dentre outras,

Movimento, Porto Alegre, v. 14, n. 01, p. 13-38, janeiro/abril de 2008. 
caracterizando o modelo médico da deficiência, que imputa, até hoje, a marca da subnormalidade às pessoas com deficiência.

Conforme Soares (1994), na prática, contudo, a efetiva implantação da Educação Física ficou restrita, até os primeiros anos da década de 1930, às escolas do Rio de Janeiro, enquanto município da corte imperial e Capital da República, e às Escolas Militares, portanto, acessível a uns poucos privilegiados.

Essa mesma autora, ao abordar o tema "Educação Física e eugenia: algumas idéias de Fernando de Azevedo" escreve que

O pensamento médico higienista, em sua vertente eugênica, atravessa o pensamento pedagógico e influencia fortemente a construção e estruturação da Educação Física no Brasil (SOARES, 1994, p. 142).

Desse modo, buscando apoio em Kehl, Soares (1994) revela a concepção eugênica da época. Para Kehl a única solução para evitar o aprofundamento do estiolamento e degeneração do povo era a aplicação das leis eugênicas. Afirmava ele ser necessário:

\begin{abstract}
[...] restringir a proliferação de infra-homens, de semi-alienados e de dementes, pela higiene do corpo e do espírito [...] [além de] fazer com que as pessoas fortes, equilibradas, inteligentes e bonitas, tenham um maior número de filhos, para que o número médio destas pessoas [...] se eleve progressivamente. (SOARES, 1994, p. 144-145).
\end{abstract}

Betti (1991) corrobora essa discussão afirmando que a Escola de Educação Física do Exército foi o principal centro divulgador desta função eugênica da Educação Física, a qual muitas vezes se confundia com a função de preparação guerreira e patriótica.

Sendo a Escola de Educação Física do Exército o principal agente formador de professores de Educação Física na época, depreende-se que os professores formados com base nessa concepção colocavam-na em prática, nas aulas de Educação Física realizada no contexto escolar não aceitando alunos com NEEs e deixando à margem os alunos menos habilidosos ou aptos. Práticas que, por sinal, se arrastam até os dias atuais.

Movimento, Porto Alegre, v. 14, n. 01, p. 13-38, janeiro/abril de 2008. 
Para Soares (1994), a "busca de status científico" para a Educação Física não pode ser tratada como via de mão única e positiva, em si, porque científica. Se, de um lado, essa busca contribuiu para conferir credibilidade e aceitação para a Educação Física, quer seja no âmbito escolar, quer seja fora dele, de outro lado, lançou as bases para a elaboração de uma concepção de Educação Física "biologicista e medicalizada", tendo, portanto, como objeto de trabalho um corpo biológico destituído de historicidade.

Para Fernando de Azevedo (apud Soares, 1994), as aulas de Educação Física não poderiam acontecer sem a presença do médico. A sua concordância com a necessidade do médico na escola, e em especial como orientador dos trabalhos a serem desenvolvidos pela Educação Física, encontra respaldo nas formulações votadas no Congresso Internacional de Educação Física, em Paris, em 1913, as quais transcrevemos:

$$
\begin{aligned}
& 1^{\circ} \text { - antes de serem submetidos à educação física } \\
& \text { todos os meninos e meninas serão examinados pelo } \\
& \text { médico-inspetor, que os classificará em normais e } \\
& \text { retardados; } \\
& 2^{\circ} \text { - os meninos normais (ou por outra parte, os } \\
& \text { regulares físicos) serão confiados ao educador físi- } \\
& \text { co sob a vigilância efetiva do médico-inspetor; (grifo } \\
& \text { da autora) } \\
& 3^{\circ} \text { - entre os retardados, aqueles aos quais for } \\
& \text { recomendável um tratamento cinésico, serão con- } \\
& \text { fiados ao médico especialista cinesioterapeuta } \\
& \text { (SOARES, 1994, p. 155, grifo nosso). }
\end{aligned}
$$

Essas formulações nos confirmam a idéia de que a Educação Física na escola, para Fernando de Azevedo, era uma questão médica e não pedagógica, na medida em que quem definia o conteúdo e "permitia" à criança participar ou não de uma aula era o médico. O professor desempenhava um papel secundário, digamos assim, um papel de auxiliar direto, um papel de executor de tarefas pensadas e fiscalizadas pelo médico.

De acordo com Ferreira Neto (1999, p. 122):

A Educação Física, como componente curricular na obra de Azevedo, pressupõe que: a) todo escolar,

Movimento, Porto Alegre, v. 14, n. 01, p. 13-38, janeiro/abril de 2008. 
antes de se envolver com tal prática, deve ser examinado por um médico; b) em caso de defeito físico, o escolar deve ser proibido de praticá-la (grifo nosso).

A partir desses fragmentos de informação sobre a inserção de pessoas com NEEs no âmbito escolar da época, é possível deduzir que a prática da Educação Física para essas pessoas, em ambiente escolar regular, de forma sistematizada, não ocorria e ainda hoje, no século XXI, muito precisa ser feito, para que venha a ocorrer de forma satisfatória.

Dentro desta concepção "biologicista" de Educação Física, baseada na abordagem positivista de ciência e no seu método de observação e comparação de resultados, a formação das séries de alunos para as aulas daquela matéria deveria, também, obedecer a critérios biológicos, ou seja: "[...] o critério da equivalência física, resultante da idade, do coeficiente de robustez, do índice do perímetro toráxico e da conformação constitucional de cada um" (SOARES, 1994, p. 157).

A escola, e particularmente a primária, passou a ser o espaço da homogeneização a partir de resultados obtidos com as fichas médicas, pedagógicas, com os testes psicológicos e de escolaridade. Os resultados desse volumoso número de fichas e testes classificavam as crianças em débeis, inteligentes, retardadas, distribuindo-as em lugares e espaços sociais determinados, na escola e na sociedade.

Por esse modelo médico, orgânico da sociedade, baseado nos ideais de eugenização da raça e promoção de saúde, as pessoas com NEEs tinham pouco ou nenhum espaço na sociedade. Quando tinham, era em espaços segregados, como as escolas para cegos e surdos criadas no Rio de Janeiro, na época do Brasil Império, no século XIX. Atualmente, no início do século XXI, esse modelo ainda se encontra hegemônico nas práticas sociais relacionadas com essas pessoas, no entanto, em processo de transição para o modelo social da deficiência. ${ }^{2}$

Soares (1994, p.161) expressa forte crítica à Educação Física desenvolvida no período estudado (1850 a 1930) e questiona “[...] se

\footnotetext{
${ }^{2}$ Modelo em que a sociedade é chamada a reconhecer que cria obstáculos à inserção das pessoas com NEEs em seu meio e, portanto, precisa se modificar para atender aos interesses e necessidades desses cidadãos e não o contrário.

Movimento, Porto Alegre, v. 14, n. 01, p. 13-38, janeiro/abril de 2008.
} 
os apelos da mídia às fórmulas frenéticas de 'cuidar do corpo' hoje não seriam a nova roupagem de um higienismo e eugenismo pósmoderno?"

Essa questão faz pensar que na sociedade atual, ainda há uma supervalorização do corpo robusto, perfeito, belo, atlético que, com a influência da mídia, ganha contornos de adoração ("corpolatria", culto ao corpo) $)^{3}$, em detrimento dos corpos considerados imperfeitos, feios, degenerados, como o corpo deficiente, obeso, sacrificado pelo trabalho árduo, pela miséria ou outra causa orgânica e social

Em 30 de junho de 1931, a Portaria $n^{\circ} 70$, do ministro Francisco Campos, recomendava para a Educação Física, a adoção das normas e diretrizes do Centro de Educação Física do Exército, baseadas no Método Francês, adotada pelas Forças Armadas brasileiras desde 1921. Esse seria o método oficialmente adotado nas escolas brasileiras, perdurando, de acordo com Betti (1991), até próximo aos anos de 1960. Em cada série, foram estabelecidos objetivos específicos, quase todos de cunho fisiológico.

Em 1940, conforme relatório da Divisão de Educação Física (DEF) citado por Betti (1991) a Educação Física no País encontravase mais bem estruturada e funcionando somente no ensino secundário. Nos outros níveis de ensino, ocorria de forma precária e era pouco existente.

Para Ferreira Neto (1999), o processo de escolarização da Educação Física nas escolas brasileiras se consolida, no século XX, especialmente, a partir do Estado Novo (1937-1945).

Conforme escreveu Betti (1991, p. 89):

\begin{abstract}
Não foi a Educação Física objeto de profundo interesse teórico; foi antes uma atividade considerada objetivamente útil pelo Estado, sempre tratada em separado nos currículos escolares. A eugenia, a higiene/saúde, a preparação militar e o nacionalismo foram os núcleos de convergência dos grupos interessados na implantação da Educação Física.
\end{abstract}

${ }^{3}$ CODO, Wanderley; SENNE, Wilson A. O que é corpo (latria)? São Paulo: Brasiliense, 1985.

Movimento, Porto Alegre, v. 14, n. 01, p. 13-38, janeiro/abril de 2008. 
No período de 1946-1968, conforme Betti (1991), a Educação Física brasileira sofreu forte influência do método criado pelo Instituto Nacional da França, denominado "Educação Física Desportiva Generalizada". O método foi difundido no Brasil pelo professor Augusto Listello, ficando conhecido como "Método Desportivo Generalizado". Resumidamente, procura incorporar o conteúdo esportivo aos métodos da Educação Física, com ênfase no aspecto lúdico.

Segundo Listello (1957, apud BETTI, 1991, p. 89), o Método Desportivo Generalizado tem como objetivos:

\begin{abstract}
a) iniciar nos diferentes esportes; b) orientar para as especializações através do desenvolvimento e aperfeiçoamento das atitudes e gestos; c) desenvolver o gosto pelo belo, pelo esforço e performance; e d) provocar as necessidades de higiene.
\end{abstract}

Soares et al. (1992, p. 54) entendem que essa influência do esporte no sistema escolar foi de tal magnitude que temos, então, "[...] não o esporte da escola mas sim o esporte na escola (grifo nosso)". Para esses autores, isso indicava

$$
\begin{aligned}
& \text { [...] a subordinação da educação física aos códigos/ } \\
& \text { sentido da instituição esportiva, caracterizando-se o } \\
& \text { esporte na escola como um prolongamento da insti- } \\
& \text { tuição esportiva: esporte olímpico, sistema } \\
& \text { desportivo nacional e internacional. Esses códigos } \\
& \text { podem ser resumidos em: princípios de rendimento } \\
& \text { atlético/desportivo, competição, comparação de ren- } \\
& \text { dimento e recordes, regulamentação rígida, sucesso } \\
& \text { no esporte como sinônimo de vitória, racionalização } \\
& \text { de meios e técnicas etc. (SOARES, 1992, p. 54) }
\end{aligned}
$$

O esporte determina, dessa forma, o conteúdo de ensino da Educação Física, a relação professor-aluno, que passa da relação professor-instrutor e aluno-recruta para a de professor-treinador e aluno-atleta, e a orientação nos princípios de racionalidade, eficiência e produtividade, princípios esses também defendidos pela Pedagogia Tecnicista muito difundida no Brasil, na década de 1970.

Pelo exposto até o momento, é possível perceber que os métodos de ensino utilizados na Educação Física (método ginástico e do

Movimento, Porto Alegre, v. 14, n. 01, p. 13-38, janeiro/abril de 2008. 
esporte performance), todos voltados, predominantemente, para o "fazer", com uma concepção de homem/corpo orientada para a eugenização da raça, numa perspectiva biológica, a-histórica e acrítica, seguindo princípios de racionalidade, eficiência e produtividade, não favoreciam a inclusão daquelas pessoas que apresentavam pouca habilidade motora e as que apresentavam algum tipo de incapacidade/deficiência.

Além disso, conforme os dados divulgados no "Diagnóstico da Educação Física e Desportos", divulgados em 1971, a Educação Física pouco existia no ensino primário e a formação profissional deixava muito a desejar.

\section{EdUCAÇÃo, EDUCAÇÃO FISICA ADAPTADA E INCLUSÃO}

A Educação Física começa a se preocupar com a atividade física e o esporte para pessoas com NEEs apenas, aproximadamente, no final dos anos de 1950, e o enfoque inicial para a prática dessas atividades foi o médico. Os programas eram denominados ginástica médica e tinham a finalidade de prevenir doenças, utilizando para tanto exercícios corretivos e de prevenção, ou seja, eram relacionados com a reabilitação (COSTA; SOUSA, 2004).

Para uma melhor compreensão da história da Educação Física Adaptada, procuramos buscar sua origem conceitual. Podemos dizer que essa expressão, "Educação Física Adaptada", surgiu na década de 1950 e foi definida pela American Association for Health, Physical Education, Recreation and Dance (AAHPERD), segundo tradução de Pedrinelli (1994) como:

\footnotetext{
Um programa diversificado de atividades desenvolvimentistas, jogos e ritmos adequados a interesses, capacidades e limitações de estudantes com deficiências que não podem se engajar com participação irrestrita, segura e bem-sucedida em atividades vigorosas de um programa de educação física geral (PEDRINELLI, 1994, apud COSTA; SOUSA, 2004, p. 29).
}

Movimento, Porto Alegre, v. 14, n. 01, p. 13-38, janeiro/abril de 2008. 
Em outras palavras, podemos dizer que um programa de Educação Física geral não conseguiu abranger a especificidade das pessoas com NEEs e, então, a Educação Física Adaptada veio para suprir essa lacuna existente, realizando uma ação paralela à Educação Física geral, desenvolvendo programas de atendimento às pessoas com NEEs em ambientes segregados e em espaço-tempo diferentes dos trabalhos realizados com pessoas que não apresentam NEEs.

Até porque, como a Educação Física poderia lidar com corpos imperfeitos, mutilados, improdutivos, convivendo com corpos considerados bonitos, perfeitos, saudáveis, se teve a sua história atravessada pela concepção "biologicista" de eugenização da raça?

Em 20 de dezembro de 1961, entrou em vigor a Lei n. 4024, de Diretrizes e Bases da Educação Nacional (LDB), apresentando, como acontecimento mais importante para a área, a definição da obrigatoriedade da Educação Física para os cursos primário e médio, até a idade de dezoito anos. Essa medida consolidou definitivamente a introdução da Educação Física no sistema escolar brasileiro de $1^{\circ}$ e $2^{\circ}$ grau.

No que concerne aos direitos da pessoa com NEEs no Brasil, segundo Jannuzzi (1989), é nessa lei que consta a primeira referência em texto legislativo a esses indivíduos. A lei descreve, no art. 88, que "[...] a educação dos excepcionais deve, no que for possível, enquadrar-se no sistema geral de educação a fim de integrá-los na comunidade" (BRASIL, 1988, p. 248).

Desde então, as conquistas legais das pessoas com NEEs vêm se ampliando, no sentido de lhes serem asseguradas condições de viver em um ambiente o menos restritivo possível e integradas à sociedade.

$\mathrm{Na}$ Educação Especial a década de 1980, especialmente em 1981, é marcada com a promulgação, pelas Nações Unidas, do Ano Internacional das Pessoas Portadoras de Deficiência, que culminou com a criação de setores específicos para cuidar dessa questão nos ministérios públicos de vários países.

Movimento, Porto Alegre, v. 14, n. 01, p. 13-38, janeiro/abril de 2008. 
Como resultado desse processo, a Constituição Federal brasileira, promulgada em 5 de outubro de 1988, que registrou o direito público subjetivo à educação de todos os brasileiros, inclusive os que apresentam NEEs, estes preferencialmente na rede regular de ensino, a questão das políticas públicas a elas destinadas tornou-se mais presente em diferentes espaços da legislação educacional da União, Estados e Municípios. As novas constituições estaduais e as leis orgânicas municipais reproduziram ou ampliaram as referências à Educação Especial.

A Lei $n^{\circ} .7 .853$, de 24 de outubro de 1989, que dispõe sobre as pessoas com NEEs, reafirmou a obrigatoriedade da oferta da Educação Especial em estabelecimentos públicos de ensino; a “[...] matricula compulsória em cursos regulares de estabelecimentos públicos e particulares de pessoas [com NEEs] capazes de se integrarem no sistema regular de ensino"; e definiu como crime o ato de "[...] recusar, suspender, procrastinar, cancelar ou fazer cessar, sem justa causa, a inscrição de alunos em estabelecimento de ensino de qualquer curso ou grau, público ou privado, por motivos derivados das [necessidades educacionais] que porta". O decreto que regulamenta a Lei, publicado dez anos depois (Decreto ${ }^{\circ}$. 3.298, de 20/ 12/1999), explicita que os serviços de Educação Especial serão ofertados nas escolas públicas ou privadas:

$$
\begin{aligned}
& \text { [...] mediante programas de apoio para o aluno } \\
& \text { que está integrado no sistema regular de ensino, ou } \\
& \text { em escolas especializadas exclusivamente quando } \\
& \text { a educação das escolas comuns não puder satisfa- } \\
& \text { zer as necessidades educativas ou sociais do aluno } \\
& \text { ou quando necessário ao bem-estar do educando } \\
& \text { (BRASIL..., 1999, p. 5). }
\end{aligned}
$$

Dessa forma, os alunos com NEEs passaram a ter o direito a matricula na escola regular em classes regulares, recebendo atendimento educacional de todos os profissionais que atuam com as respectivas turmas. Essa situação nova para os profissionais da educação passou a ser um desafio e um problema ao mesmo tempo. Um desafio, no sentido de buscar os meios para educar a todos indistintamente, no mesmo espaço-tempo. Um problema, no sentido

Movimento, Porto Alegre, v. 14, n. 01, p. 13-38, janeiro/abril de 2008. 
da desinformação, da falta de estrutura das escolas, do despreparo profissional, em função de não ter estudado o assunto na graduação $\mathrm{e}$, de repente, se verem às voltas com o ensino de crianças que apresentam características tão peculiares.

A luta para que as pessoas com NEEs contem com as mesmas condições educacionais que o conjunto da população, tem como referência, dentre outras, a Declaração dos Direitos do Homem, de 1948, na qual se afirma que "[...] todo homem tem direito à instrução" (DECLARAÇÃO..., 1988, art. XXVI). Esse direito foi reafirmado com a proclamação da Declaração dos Direitos das Pessoas Deficientes (1975), com a Convenção Internacional sobre os Direitos da Criança (1989), com o Estatuto da Criança e do Adolescente (1990) e com a Declaração Mundial sobre Educação para Todos (1990).

A Declaração de Salamanca, resultante da Conferência Mundial sobre Necessidades Educativas Especiais: acesso e qualidade, realizada de 7 a 10 de junho de 1994, na Espanha, esclarece:

$$
\begin{aligned}
& \text { [...] o princípio da [inclusão]" e pauta-se “[...] no } \\
& \text { reconhecimento das necessidades de ação para con- } \\
& \text { seguir 'escolas para todos', isto é, instituições que } \\
& \text { incluam todo mundo, reconheçam as diferenças, pro- } \\
& \text { movam a aprendizagem e atendam às necessidades } \\
& \text { de cada um. (DECLARAÇÃO..., 1994) }
\end{aligned}
$$

A homologação no Brasil da Lei de Diretrizes e Bases (LDB) $\mathrm{n}^{\circ}$. 9.394, de 24 de dezembro de 1996, fortemente influenciada pela Declaração Mundial sobre Educação para Todos (1990) e pelas recomendações da Declaração de Salamanca (1994), desencadeou amplo processo de mudanças no sistema educacional, nos diferentes níveis e modalidades de ensino. Uma dessas mudanças foi a implantação da política de inclusão das pessoas com NEEs na rede regular de ensino, modificando a sistemática de atendimento adotada até então, que segregava essas pessoas em instituições especializadas e em classes especiais.

Com a aprovação dessa lei e com o acordo feito em Salamanca, consolidou-se a proposta da educação inclusiva, segundo a qual as pessoas com NEEs devem participar em condições de iguais do

Movimento, Porto Alegre, v. 14, n. 01, p. 13-38, janeiro/abril de 2008. 
processo educativo das escolas regulares, juntamente com as demais pessoas. A escola de qualquer nível ou modalidade passa a ser uma só e para todos, sem qualquer discriminação, prescreve a lei.

Posteriormente, foram lançados outros documentos complementares à Lei 9394/96. Dentre os principais, citamos: o Plano Nacional de Educação, Lei n ${ }^{\circ} 10.172$, de 9 de janeiro de 2001 (BRASIL, 2001); o Parecer n ${ }^{\circ}$ 17, de 3 de julho de 2001 (BRASIL, 2001b), documento que fundamenta a Resolução 2/01; a Resolução CNE/ CEB $\mathrm{n}^{\circ} 2$, de 11 de setembro de 2001, que institui as Diretrizes Nacionais para a Educação Especial na Educação Básica; os Parâmetros Curriculares Nacionais (PCNs): Adaptações Curriculares, estratégias para educação de alunos com necessidades educacionais especiais (1999); e os PCNs (2002), relacionados com a Educação Física de $5^{\mathrm{a}}$. a $8^{\mathrm{a}}$. série.

Mesmo contando com todos esses documentos, conforme Prieto (2003) estamos longe de atingir a quantidade total e a qualidade social no atendimento escolar dispensado aos alunos com NEEs. Citando Odeh (2000) a autora afirma que, "[...] na melhor das hipóteses, o índice de atendimento escolar dessa população não ultrapassa a 10\%" (PRIETO, 2003, p. 3).

Diante dessa conjuntura, o movimento pela educação inclusiva tem gerado reações na esfera educacional: dúvidas, questionamentos, debates, profissionais demonstrando desespero e ávidos por orientação e informações. Enfim, o que fazer? Como fazer? São as questões de ordem.

Essa tendência inclusivista no cenário político educacional brasileiro, tem deixado os dirigentes educacionais confusos diante da obrigação de ter que trabalhar, no mesmo espaço e tempo, com crianças que apresentam as mais diferentes formas de habilidades, capacidades, comportamentos e histórias de vida. O ideário da igualdade universal entre os homens começa a dar sinais de exaustão e um novo discurso começa a se tornar hegemônico. Estamos falando das diferenças concretas existentes entre os homens, que sempre existiram, porém foram negadas ou desconsideradas pela grande maioria dos educadores (CARMO, 2002).

Movimento, Porto Alegre, v. 14, n. 01, p. 13-38, janeiro/abril de 2008. 
Essa situação afeta os professores indistintamente. No caso dos professores de Educação Física não é diferente. As pesquisas indicam que o despreparo profissional e a desinformação são apontados, pela grande maioria dos profissionais da educação, como a causa do não atendimento educacional dos alunos com NEEs que freqüentam as classes regulares.

Com isso, está havendo um forte movimento em prol da formação inicial e continuada dos profissionais da educação, com o objetivo de qualificá-los para atender à diversidade encontrada no interior da escola.

No âmbito escolar, a inclusão de alunos com NEEs nas aulas de Educação Física, a nosso ver, parece estar relacionada, predominantemente, com aspectos atitudinais e procedimentais. O primeiro diz respeito ao preparo profissional, à concepção de homem que se quer formar, à atitude de aceitação e promoção da diversidade humana. O segundo está no caminho, no meio para atingir os objetivos, ou seja, a escolha da metodologia de ensino, dos procedimentos didáticos.

Nesse sentido, concordando com Landim (2003) consideramos que uma proposta para a Educação Física deve respeitar a diversidade humana em qualquer de suas expressões: gênero, biótipo, cor, raça, deficiência, etnia, sexualidade, aceitando e elegendo as diferenças individuais como fator de enriquecimento cultural. Desse modo, será possibilitada, a todas as crianças da escola, maior oportunidade de aprendizagem, interação com seu meio sociocultural e uma convivência positiva e rica entre todos os alunos.

Sendo assim, entendemos que incluir na Educação Física não é simplesmente adaptar essa disciplina escolar para que uma pessoa com NEEs possa participar da aula, mas é adotar uma perspectiva educacional cujos objetivos, conteúdos e métodos valorizem a diversidade humana e que esteja comprometida com a construção de uma sociedade inclusiva.

Nesse sentido, os aspectos da formação dos professores de Educação Física em NEEs, conforme Rodrigues (2005) deixam em Portugal, muito a desejar e podemos afirmar que o mesmo se aplica ao Brasil.

Movimento, Porto Alegre, v. 14, n. 01, p. 13-38, janeiro/abril de 2008. 
A partir da análise dos programas de seis escolas de formação em Portugal, o autor verificou que a formação inicial é de caráter geral e, raramente, relacionada com aspectos concretos de inclusão em Educação Física. Observou que:

\begin{abstract}
Existem muitos itens programáticos relacionados com a caracterização da deficiência e com aspectos institucionais mas poucos relacionados com boas práticas e metodologias que facilitem a integração e inclusão. Noutros casos são contemplados conteúdos relacionados com modalidades de Desporto Adaptado, conteúdos que só remotamente poderão ter uma aplicação a casos de inclusão (RODRIGUES, 2005, p. 8).
\end{abstract}

No Brasil, somente a partir do Parecer $\mathrm{n}^{\circ}$. 215, de 11 de março de 1987 (BRASIL, 2001b), do Conselho Federal de Educação, a disciplina Educação Física Adaptada foi elencada, dentre outras, como sugestão para compor os novos currículos dos Cursos de Graduação em Educação Física, que deveriam começar a funcionar no início da década de 1990. Ela prevê a atuação do professor de Educação Física com as pessoas que apresentam NEEs. Em nosso entendimento, essa é uma das razões pelas quais muitos professores de Educação Física, hoje atuantes nas escolas, não receberam em sua formação conteúdos e/ou assuntos pertinentes à Educação Física adaptada ou à inclusão.

Cabe ressaltar, ainda, que até o final da década de 1980, as pessoas com deficiência, obesas e de baixo desempenho motor eram impedidas de ingressar nos cursos de graduação em Educação Física, por causa do teste de aptidão física que era realizado como parte do processo vestibular. Somente a partir da extinção do teste de aptidão física, no início da década de 1990, essas pessoas passaram a ter a possibilidade de realizar o vestibular para o curso de graduação em Educação Física em condições semelhantes aos demais participantes.

Nessa concepção, os cursos de graduação em Educação Física, estavam abertos, predominantemente, às pessoas que apresentavam corpo atlético, robusto. A ênfase era no "fazer" em detrimento da formação do pensamento "crítico-reflexivo". O entendimento

Movimento, Porto Alegre, v. 14, n. 01, p. 13-38, janeiro/abril de 2008. 
era o de que somente aquele que soubesse demonstrar a tarefa ao seu aluno podia se tornar professor de Educação Física.

Dessa forma, influenciados pela formação recebida, desenvolveram posturas discriminadoras, uma vez que o trabalho estava voltado aos mais habilitados e talentosos. Os não aptos na obtenção de tal rendimento eram simplesmente deixados de lado, como é possível constatar, em pleno século XXI, com bastante freqüência, em muitas práticas escolares no País.

Além disso, concordando com Ribeiro e Araújo (2004), temos que reconhecer que nem sempre há uma identificação dos futuros profissionais com a área de Educação Física Adaptada, por motivos diversos.

\begin{abstract}
Neste momento, cabe dizer que uma causa provável seja ainda a dificuldade em se trabalhar com as diferenças, com o corpo não-perfeito, 'incapaz' de atingir o rendimento que se está acostumado a atingir em situações de 'normalidade'. Isso constitui, provavelmente, resquício de uma Educação Física tecnicista, ou mesmo o fato de a formação de professor de Educação Física ser realizada em cursos de graduação que, ainda, representam essa característica. (RIBEIRO; ARAÚJO, 2004, p. 20-21),
\end{abstract}

Visando a apontar essa realidade existente nos cursos de graduação, Tani (2000, p. 87) afirma que "[...] os cursos de graduação, salvo raras exceções, oferecem uma formação eminentemente técnica em que o aprender a fazer predomina sobre o conhecer".

Em seus estudos, Rodrigues (2005) mostra ter encontrado na Educação Física uma dupla genealogia de razões que podem conduzir à exclusão, com as quais concordamos plenamente. Por um lado a Educação Física desenvolve-se numa escola que tem uma cultura que possibilita a exclusão de todos os que não se enquadrem nos padrões esperados, como podemos observar nas taxas de abandono e insucesso escolar. Por outro lado, a cultura desportiva e competitiva, dominante nas propostas curriculares da Educação Física cria um obstáculo adicional à inclusão de alunos que são inicialmente

Movimento, Porto Alegre, v. 14, n. 01, p. 13-38, janeiro/abril de 2008. 
encarados como menos capazes para um bom desempenho (por várias razões) numa competição.

Costa e Sousa (2004) corroboram essa discussão ao explicitarem que são inegáveis as contribuições trazidas pela Educação Física Adaptada como área do conhecimento e prática de atividade física e desportiva pelas pessoas com NEEs, porém não deixaram de explicitar o caráter segregacionista existente nessas práticas, ficando evidente na medida em que são vivenciados somente por grupos de pessoas que apresentam NEEs.

Os autores citados verificaram que a integração ${ }^{4}$ das pessoas com NEEs pôde tornar-se uma realidade por meio da prática de atividade física e desportiva, participando de eventos nacionais e internacionais, chegando à realização das paraolimpíadas. ${ }^{5}$ Porém, não deixaram de enfatizar que essa integração, apesar de concreta, é apenas de uma minoria, considerando que, tanto para os ditos "normais" nas olimpíadas como para as pessoas que apresentam NEEs nas paraolímpiadas, a efetiva participação é de uma minoria.

Também temos que considerar que a Educação Física na integração conseguiu enxergar a potencialidade, valorizar a diferença, superar a visão de corpo imperfeito, mutilado, ineficaz, adaptando os esportes e as atividades físicas para que as pessoas com NEEs pudessem praticá-las. Com isso, as que tiveram acesso aos esportes atingiram um razoável estágio em termos de acesso, participação e desenvolvimento físico desportivo. No entanto, concordamos com Carmo (2002), quando afirma que a educação Física não está preparada para tratar o uno e o diverso simultaneamente, conforme aponta a proposta de inclusão. Seus conteúdos estão parados no tempo, o que a obriga a recorrer às adaptações.

Não negamos a importância histórica da Educação Física e dos esportes adaptados para as pessoas com NEEs, apenas entendemos que a diversidade e a bilateralidade entre as pessoas com

\footnotetext{
${ }^{4}$ Proposta na qual às pessoas com NEEs devem ser preparadas para serem inseridas no contexto social. Essa proposta teve seu desenvolvimento na década de 1970 e 1980, encontrando-se atualmente em processo de transição para a proposta inclusivista.

${ }_{5}^{5}$ De acordo com Alencar, citado por Costa e Sousa (2004), o Brasil participa dos Jogos Paraolímpicos desde 1972
}

Movimento, Porto Alegre, v. 14, n. 01, p. 13-38, janeiro/abril de 2008. 
NEEs e as pessoas que não apresentam NEEs devem fazer parte do mesmo espaço-tempo de convivência, para que alcancemos os princípios da inclusão.

Nesse sentido, a Educação Física pode ser vista de diferentes maneiras. De acordo com Sousa (2002, p. 37),

$$
\begin{aligned}
& \text { [...] por um lado, pode lidar com ideologias } \\
& \text { 'biologicistas', que se preocupam com a estética } \\
& \text { ou o rendimento físico e técnico do indivíduo e, } \\
& \text { por outro, pode se propor a trabalhar enfatizando } \\
& \text { os aspectos histórico-sociais do indivíduo. }
\end{aligned}
$$

Dependendo da forma de conceber a Educação Física, não é difícil legitimar a exclusão de alunos de determinadas atividades, apresentem eles NEEs ou não. Já vivenciamos muitas vezes a exclusão disfarçada dos menos hábeis, dos mais gordinhos, dos mais lentos, enfim, daqueles que não se enquadram em um padrão preestabelecido.

\section{CONSIDERAÇõES FINAIS}

A área da Educação Física e dos esportes dirigidos às pessoas com NEEs mostrou, nas duas últimas décadas do século XX e início do século XXI, progressos notáveis. Podemos destacar a fundação da Sociedade Brasileira de Atividade Motora Adaptada (SOBAMA), a criação de um Grupo de Trabalho nos Congressos da Associação Nacional dos Pesquisadores em Educação (ANPED) e do Colégio Brasileiro de Ciências do Esporte (CBCE), a inclusão de disciplinas de Educação Física Adaptada nos currículos dos Cursos de Graduação em Educação Física e de várias linhas de pesquisa nos Programas de Mestrado e Doutorado no Brasil, tanto na Educação quanto em Educação Física, o fortalecimento do Comitê Paraolímpico Brasileiro. As grandes conquistas dos atletas nas últimas paraolímpiadas, em Sidney na Austrália e em Atenas na Grécia, exemplificam nossas afirmações.

Mas, apesar dos avanços, não podemos negar que ainda é realidade, em algumas escolas, aulas de Educação Física separadas por turmas, tendo como parâmetro o sexo e o nível de habilidade

Movimento, Porto Alegre, v. 14, n. 01, p. 13-38, janeiro/abril de 2008. 
motora, demonstrando, nitidamente, a bagagem histórica, cultural, social e educativa que nos acompanha.

Muitas vezes, esses princípios vêm contribuir fortemente para o processo de exclusão escolar desses alunos. Assim, ao excluir, perdemos a oportunidade de aprender e conviver com o diferente.

\begin{abstract}
Alijando-se o aluno com [NEEs] da [inclusão] social, este perde em desenvolvimento, enquanto a sociedade perde por não ter a oportunidade e a possibilidade de aprender com uma significativa parcela de seus elementos constitutivos, representados pelos 'diferentes' segregados. Com isso, todos perdemos em consciência, em comportamento e, conseqüentemente, em possibilidade de transformação (ARANHA apud CRUZ, 1996, p.12).
\end{abstract}

Considerando os novos rumos da Educação Especial para o século XXI, ou seja, a perspectiva de inclusão, não podemos mais pensar em Educação Especial desvinculada da educação geral. E o mesmo ocorrendo com a Educação Física adaptada que, em nosso entendimento, não pode mais ficar desvinculada da Educação Física geral.

Rodrigues (2005) aponta algumas sugestões que eventualmente permitirão avanços na proposta de Educação Física inclusiva na escola, a saber:

a) O estudo da cultura corporal de movimento proporcionada através da disciplina curricular de Educação Física é um direito. Não é uma opção descartável. Porque é um direito o nosso ponto de partida tem de ser que nenhum aluno pode ser dispensado dele.

b) A formação inicial e contínua tem de seguir modelos isomórficos, isto é, o futuro profissional tem de ser formado para conhecer e aplicar conteúdos que estejam relacionados com o que se pretende que ele venha a ser como profissional. Se os futuros profissionais forem formados para fomentar a competição, para procurarem grupos homogêneos, para a exaltação do trabalho individual como poderemos esperar que este profissional incentive nos seus alunos a cooperação, o respeito e o valor da diferença e a solidariedade?

Movimento, Porto Alegre, v. 14, n. 01, p. 13-38, janeiro/abril de 2008. 
c) A área de Educação Física pode, com rigor e com investimento, ser efetivamente uma área-chave para tornar a educação mais inclusiva e pode mesmo, ser um campo privilegiado de experimentação, de inovação e de melhoria da qualidade pedagógica na escola.

Nessa direção, entendemos, como Costa e Sousa (2004), que é preciso romper com a atual organicidade escolar, buscar novos princípios filosóficos como diretriz para a Educação/Educação Física, procurando entender que os homens são diferentes e é na diferença que ocorre a compreensão dos seus limites e possibilidades. É preciso redimensionar o tempo e o espaço do trabalho escolar, flexibilizar os conteúdos, rompendo com a compartimentalização dos saberes, e ainda aprender a lidar com o uno e o diverso simultaneamente, que é, em nosso entendimento, o grande desafio para a Educação/Educação Física neste século XXI.

Movimento, Porto Alegre, v. 14, n. 01, p. 13-38, janeiro/abril de 2008. 


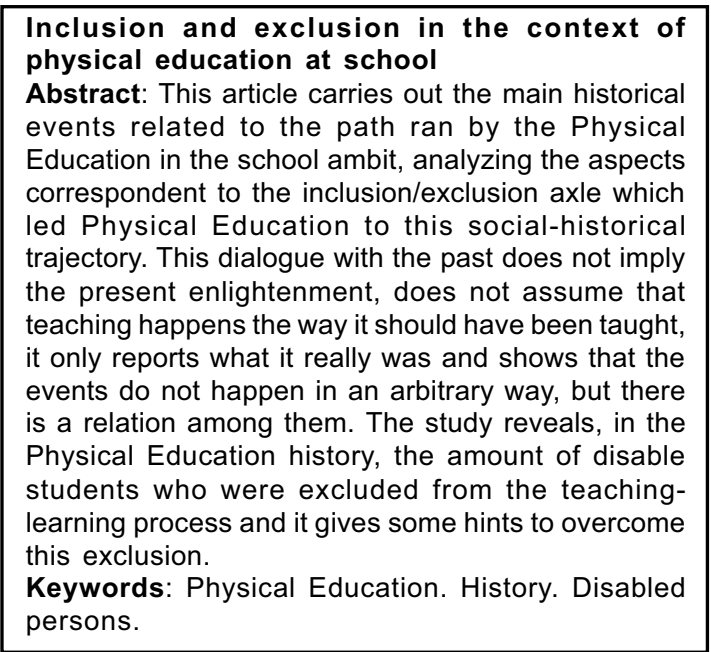

Inclussión y exclussión en el contexto de la educación física escolar

Resumen: Este artículo apunta los principales acontecimientos históricos cuanto al camino recorrido por la Educación Física en el ámbito escolar, analizando aspectos relacionados con el eje inclusión/exclusión que permeó la Educación Física a lo largo de esa trayectoria socio-histórica. Ese diálogo con el pasado no implica que él aclare el presente, no supone que él enseñe como debería tener sido; solamente relata el que fue y muestra que los acontecimientos no se dan de forma arbitraria, pero existe relación entre ellos. El estudio revela, el cuanto en la historia de la Educación Física los alumnos con deficiencia fueron excluidos del proceso enseñanzaaprendizaje y deja pistas para la superación de esa exclusión.

Palabras-clave:. Educación Física. Historia. Personas con discapacidad.

\section{REFERÊNCIAS}

BETTI, Mauro. Educação Física e sociedade: a educação física na escola brasileira de $1^{\circ}$ e $2^{\circ}$ graus. São Paulo: Movimento, 1991.

Movimento, Porto Alegre, v. 14, n. 01, p. 13-38, janeiro/abril de 2008. 
BRASIL. CONSELHO NACIONAL DE EDUCAÇÃO/CÂMARA DE EDUCAÇÃO BÁSICA. Resolução $n^{\circ}$ 2, de 11 de setembro de 2001: Institui as Diretrizes Nacionais para a Educação Especial na Educação Básica. Diário [da] República Federativa do Brasil, Brasília, 14 set. 2001a.

BRASIL. CONSELHO NACIONAL DE EDUCAÇÃO. CÂMARA DE EDUCAÇÃO BÁSICA. Parecer $n^{\circ}$. 17, de 03 de julho de 2001. Brasília, SEESP/MEC, 2001b.

BRASIL. Constituição (1988). Constituição [da] República Federativa do Brasil. Brasília: Senado Federal, 1988.

BRASIL. Decreto-lei $n^{\circ} 3.298$, de 20 de dezembro de 1999. Estatuto das Pessoas com Deficiência. Diário Oficial [da] República Federativa do Brasil. Brasília, 21 dez. 1999.

BRASIL. Lei n. 4.024/61 de 20 de dezembro de 1961. Lei de Diretrizes e Bases da Educação Nacional. In: BREJON, Moysés (Org.) Estrutura e funcionamento do ensino de $1^{\circ}$ e $2^{\circ}$ graus. 20. ed. São Paulo: Pioneira, 1988. p. 243-251.

BRASIL. Lei $n^{\circ} 10.098$, de 19 de dezembro de 2000. Estabelece normas gerais e critérios básicos para a promoção da acessibilidade das pessoas portadoras de deficiência ou com mobilidade reduzida. Disponível em: < http:// www.pgj.ce.gov.br/centros/caogsdat/lei1098.doc.>. Acesso em: 2 jul. 2004.

BRASIL. Lei $\mathbf{n}^{\circ}$ 10.172, de 9 de janeiro de 2001. Dispõe sobre o Plano Nacional de Educação. Diário Oficial [da] República Federativa do Brasil, Brasília, 10 jan. 2001.

BRASIL. Lei $\mathbf{n}^{\circ} \mathbf{7 . 8 5 3}$, de 24 de outubro de 1989. Dispõe sobre o apoio às pessoas portadoras de deficiência, sua integração social, sobre a Coordenadoria Nacional para Integração da Pessoa Portadora de Deficiência. Brasília: CORDE, 1994.

BRASIL. Lei $n^{\circ} \mathbf{8 . 0 6 9}$, de 13 de julho de 1990. Estatuto da Criança e do Adolescente. Vitória: DIO, 1990.

BRASIL. Lei $\mathrm{n}^{\circ}$ 9.394, de 24 de dezembro de 1996. Dispõe sobre as Diretrizes e Bases da Educação Nacional (LDB). Brasília: Gabinete do Senador Darcy Ribeiro, 1997.

BRASIL. Ministério da Educação. Secretaria de Educação Fundamental. Parâmetros Curriculares Nacionais: terceiro e quarto ciclos do ensino fundamental - Educação Física. (5 a $8^{\mathrm{a}}$ série). 3. ed. Brasília: MEC/SEF, 2002.

BRASIL. Ministério da Educação. Secretaria de Educação Fundamental. Secretaria de Educação Especial. Parâmetros Curriculares Nacionais adaptações curriculares - estratégias para a educação de alunos com necessidades educativas especiais. Brasília: MEC/SEF/SEESP, 1999.

BRASIL. Portaria Ministerial $n^{\circ}$ 1.793, de 27 de dezembro de 1994. Brasília: Ministério da Educação, 27 dez. 1994.

Movimento, Porto Alegre, v. 14, n. 01, p. 13-38, janeiro/abril de 2008. 
CARMO, Apolônio Abadio do. Inclusão escolar e a educação física: que movimentos são estes? Revista Integração, Brasília, v. 14, p. 6-13, mar. 2002. (Edição especial: Educação Física Adaptada).

CASTELLANI FILHO, Lino. Educação física no Brasil: a história que não se conta. Campinas, SP: Papirus, 1988.

CODO, Wanderley; SENNE, Wilson A. O que é corpo (latria)? São Paulo: Brasiliense, 1985.

CONVENÇÃO Sobre os direitos da Criança. Adotado em Assembléia Geral das Nações Unidas em 20 de novembro de 1989: Carta Magna Para as Crianças de Todo o Mundo. Disponível em: <http://www.unicef.org/brazil/dir-cr.htm>. Acesso em: 2 ago. 2004

COSTA, Alberto Martins; SOUSA, Sônia Bertoni. Educação física e esporte adaptado: história, avanços e retrocessos em relação aos princípios da integração/inclusão e perspectivas para o século XXI. Revista Brasileira de Ciências do Esporte, Campinas, v. 25, n. 3, p. 27-42, 2004

CRUZ, Gilmar de Carvalho. Classe especial e regular no contexto da educação física: segregar ou integrar? 1996. 80 f. Dissertação (Mestrado em Educação) - Universidade Estadual do Rio de Janeiro, Rio de Janeiro, 1996.

DECLARAÇÃO de Salamanca e linha de ação sobre necessidades educativas especiais. Brasília: CORDE, 1994.

DECLARAÇÃO dos Direitos das Pessoas Deficientes. Resolução aprovada pela Assembléia Geral das Nações Unidas em 9 de dezembro de 1975. Disponível em: <http://www.infojus.com.br/area3/ant\%f4niosilveira.htm>. Acesso em: 2 ago. 2004.

DECLARAÇÃo Mundial Sobre Educação Para Todos. Plano de Ação Para Satisfazer as Necessidades Básicas de Aprendizagem. Brasília: CORDE, 1990.

DECLARAÇÃO Universal dos Direitos Humanos. Adotada e proclamada pela Resolução $n^{\circ} 217$ A (III) da Assembléia Geral das Nações Unidas, de 10 de dezembro de 1948. Brasília: Secretaria Nacional dos Direitos Humanos do Ministério da Justiça, 1998.

FERREIRA NETO, Amarílio. A pedagogia no exército e na escola: a educação física brasileira (1880-1950). Aracruz, ES: FACHA, 1999.

JANNUZZI, Gilberta. Por uma Lei de Diretrizes e Bases que propicie a educação escolar aos intitulados deficientes mentais. Cadernos CEDES, São Paulo, n. 23, p. 17-28, 1989.

NOGUEIRA, Maria Alice. Educação, saber, produção em Marx e Engels. São Paulo: Cortez/Autores Associados, 1990.

PRIETO, Rosângela Gavioli. Políticas de melhoria da escola pública para todos: tensões atuais. In: REUNIÃO ANUAL DA ASSOCIAÇÃO NACIONAL DE

Movimento, Porto Alegre, v. 14, n. 01, p. 13-38, janeiro/abril de 2008. 
PESQUISADORES DE PÓS-GRADUAÇÃO EM EDUCAÇÃO, 26., 2003. Poços de Caldas, MG. Anais... Poços de Caldas, MG: ANPED, 2003. 1 CD-ROM. GT 15.

RIBEIRO, Sonia Maria; ARAÚJO, Paulo Ferreira de. A formação acadêmica refletindo na expansão do desporto adaptado: uma abordagem brasileira. Revista Brasileira de Ciências do Esporte, Campinas, v. 25, n. 3, p. 57-69, maio 2004.

RODRIGUES, David. A educação física perante a educação inclusiva: reflexões conceptuais e metodológicas. Publicado no boletim da Sociedade Portuguesa de Educação Física, 24/25, p. 73-81. Disponível em: < http:// www.rc.unesp.br/ib/efisica/sobama/sobamaorg/inicio.htm>. Acesso em: $20 \mathrm{fev}$. 2005.

SOARES, Carmem Lúcia et al. Metodologia do ensino da educação física. São Paulo: Cortez, 1992.

SOARES, Carmem Lúcia. Educação Física: raízes européias e Brasil. Campinas, SP: Autores Associados, 1994. (Coleção educação contemporânea).

SOUSA, Sônia Bertoni. Educação Física inclusiva: um grande desafio para o século XXI. Revista Integração, Brasília, v. 14, p. 35-38, mar. 2002.

TANI, Go. Os desafios da pós-graduação em educação física. Revista Brasileira de Ciências do Esporte, Campinas, v. 22, n. 1, p. 79-89, set. 2000. 